\title{
The miR-183/ltgA3 axis is a key regulator of prosensory area during early inner ear development
}

\author{
Priscilla Van den Ackerveken ${ }^{1,2}$, Anaïs Mounier ${ }^{1,2}$, Aurelia Huyghe ${ }^{1}$, Rosalie Sacheli ${ }^{1}$, Pierre-Bernard Vanlerberghe ${ }^{1}$, \\ Marie-Laure Volvert ${ }^{1}$, Laurence Delacroix ${ }^{1}$, Laurent Nguyen ${ }^{1}$ and Brigitte Malgrange ${ }^{\star, 1}$
}

MicroRNAs are important regulators of gene expression and are involved in cellular processes such as proliferation or differentiation, particularly during development of numerous organs including the inner ear. However, it remains unknown if miRNAs are required during the earliest stages of otocyst and cochlear duct development. Here, we report that a conditional loss of Dicer expression in the otocyst impairs the early development of the inner ear as a result of the accumulation of DNA damage that trigger p53-mediated apoptosis. Moreover, cochlear progenitors in the prosensory domain do not exit the cell cycle. Our unbiased approach identified ItgA3 as a target of miR-183, which are both enriched in the otic vesicle. We observed that the repression of integrin alpha 3 by miR-183 controls cell proliferation in the developing cochlea. Collectively, our results reveal that Dicer and miRNAs play essential roles in the regulation of early inner ear development.

Cell Death and Differentiation (2017) 24, 2054-2065; doi:10.1038/cdd.2017.127; published online 4 August 2017

The organ of Corti, located in the cochlea, is a sensory epithelium composed of the mechanosensory hair cells (HCs) and supporting cells (SCs). HCs are connected to spiral ganglion neurons, which relay acoustic information to the auditory cortex. In mice, at embryonic stage E8.5, the cochlea arises from the otic placode, a thickening of surface ectoderm. Then, the placode invaginates to form an otic vesicle, that is, the otocyst. As early as E9, neuroblasts begin to delaminate from the vesicle and migrate to form the cochleo-vestibular ganglion. In the meantime, the otocyst undergoes a series of morphologic rearrangements to generate the complex structure of the cochlea. Although considerable progress has been made in the identification of factors mediating these events, our understanding of the developmental mechanisms of this structure remains limited.

MicroRNAs (miRNAs) are a class of endogenously expressed noncoding RNAs of 21-22 nucleotides. To produce mature miRNAs, the RNase III endoribonuclease Dicer cleaves pre-miRNAs into double-strand miRNAs in the cytoplasm. Once mature, miRNAs inhibit the translation of target genes by pairing with the 3'UTR of the repressed mRNA. ${ }^{1,2}$ miRNAs have a variety of targets ${ }^{3-5}$ and have essential roles in several cellular processes, such as organogenesis, migration, cell differentiation and proliferation, ${ }^{6,7}$ demonstrating a crucial role of these small noncoding RNAs during the development of many organs including the inner ear. $^{8-10}$

Previous studies have demonstrated the importance of miRNAs during inner ear development. Hundreds of miRNAs are expressed in the inner ear ${ }^{11-14}$ but only some of them show a specific expression pattern during development of inner ear and postnatally. ${ }^{5,14-18}$ Amongst them, some
miRNAs promote neurogenesis, morphogenesis, as well as differentiation and survival of HCs. ${ }^{16,19-22}$ MiR-96, a miRNA expressed specifically in the HCs, was the first miRNA found to be associated with deafness. ${ }^{23-25}$ However, despite the important progress made to elucidate the importance of miRNA regulation for inner ear development, the genes regulated by these small RNAs remain unknown in most cases.

Here, we have investigated the role of miRNAs during the development of the otic vesicle using a Dicer conditional knockout mouse line (FoxG1-cre+/-; Dicer flox/flox, that is, Dicer-cKO). We observed DNA damage, p53 activation and finally apoptosis but also important defects of proliferation in the prosensory domain of the cochlea. By microarray analysis, we identified a cohort of mRNAs that are upregulated in Dicer mutant mice. Among them, the integrin alpha $3(\operatorname{ltg} A 3)$ is specifically expressed in the otic vesicle and its expression is significantly increased in the developing cochlear duct of Dicer-cKO mice. Interestingly, the members of the miR-183 family (miR-96, miR-182 and MiR-183) are expressed early during the otocyst development and restricted to HCs when they begin their differentiation. ${ }^{15,26}$ We uncovered that miR-183 controls the early development of the inner ear by specifically targeting ItgA3. Our present study reveals, for the first time, that Dicer and miRNAs play essential roles in the regulation of early inner ear development.

\section{Results}

Loss of mature miRNAs induces cell death and defects in inner ear morphogenesis. To elucidate the role of Dicer during the early development of the inner ear, we generated Dicer-cKO mice by crossing Dicer flox/flox mice ${ }^{27}$ with

${ }^{1}$ GIGA-Neurosciences, Interdisciplinary Cluster for Applied Genoproteomics (GIGA-R), University of Liège, C.H.U. Sart Tilman, Liège B-4000, Belgium

${ }^{*}$ Corresponding author: B Malgrange, GIGA-Neurosciences, Interdisciplinary Cluster for Applied Genoproteomics (GIGA-R), University of Liège, C.H.U. Sart Tilman, Liège B-4000, Belgium. Tel: +324 366590 5; Fax: +32 0436659 53; E-mail: bmalgrange@ulg.ac.be

${ }^{2}$ These authors are co-first authors and equally contributed to this work.

Received 05.5.17; revised 15.6.17; accepted 30.6.17; Edited by P Bouillet; published online 04.8.17 

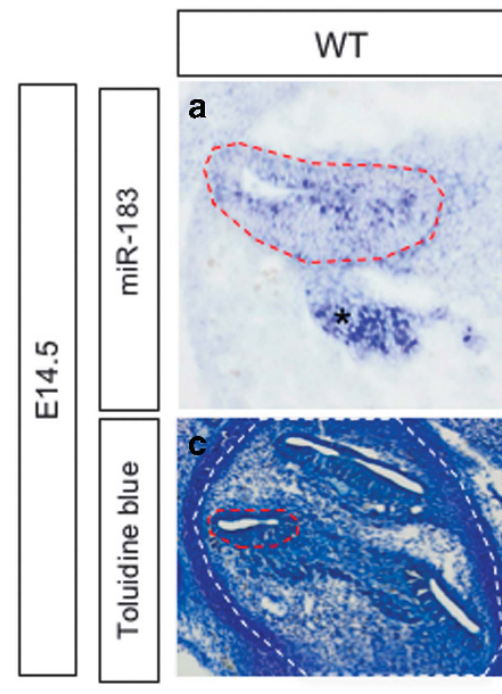

\section{a}

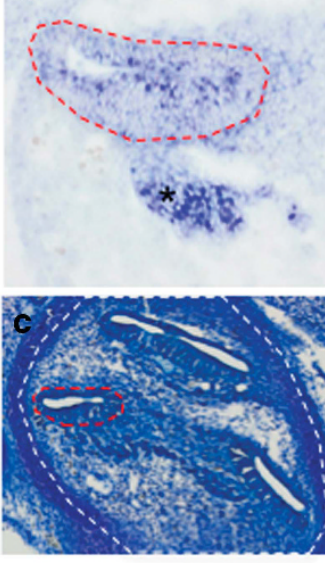

b
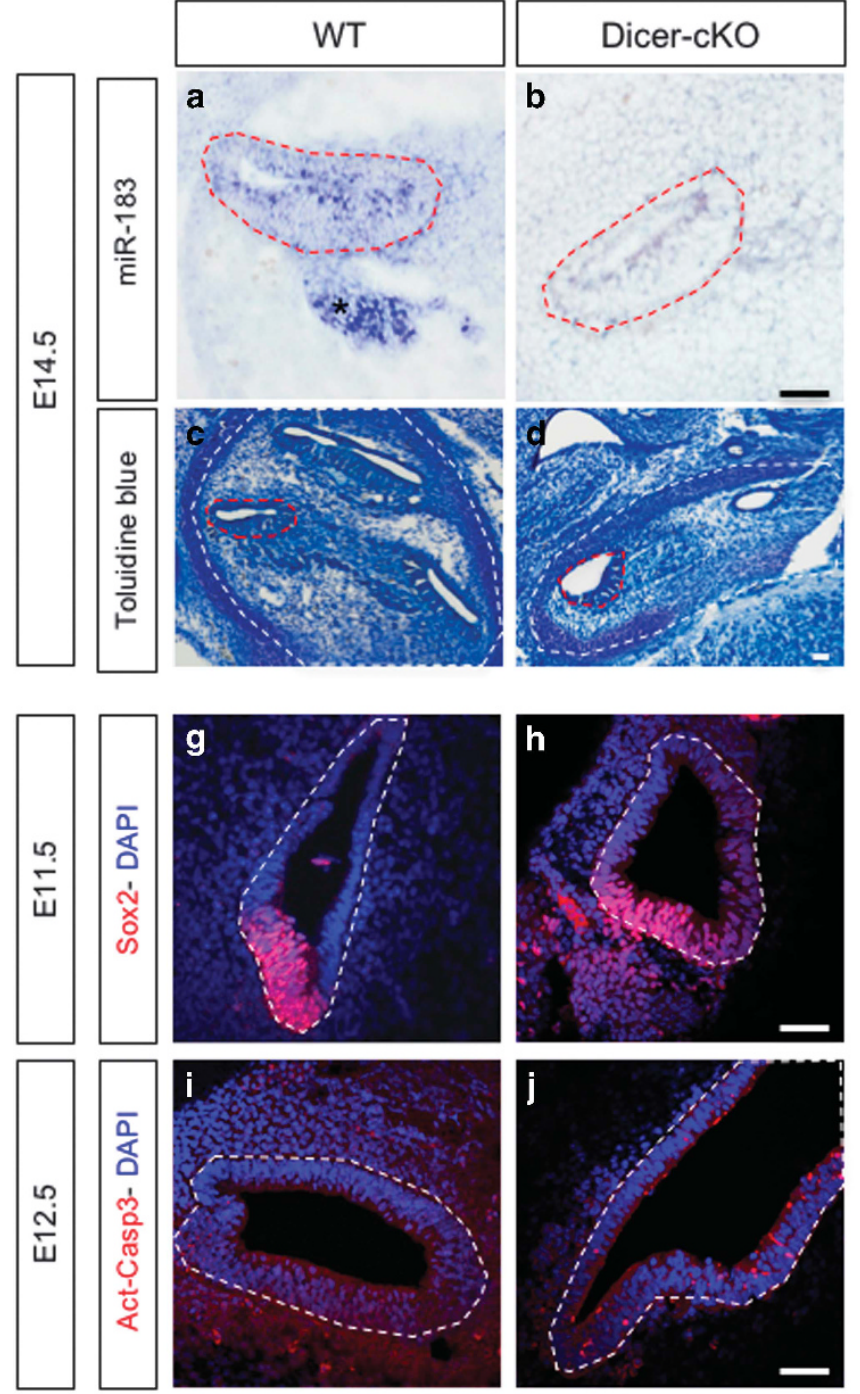

e

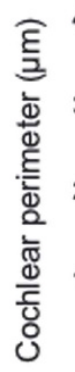
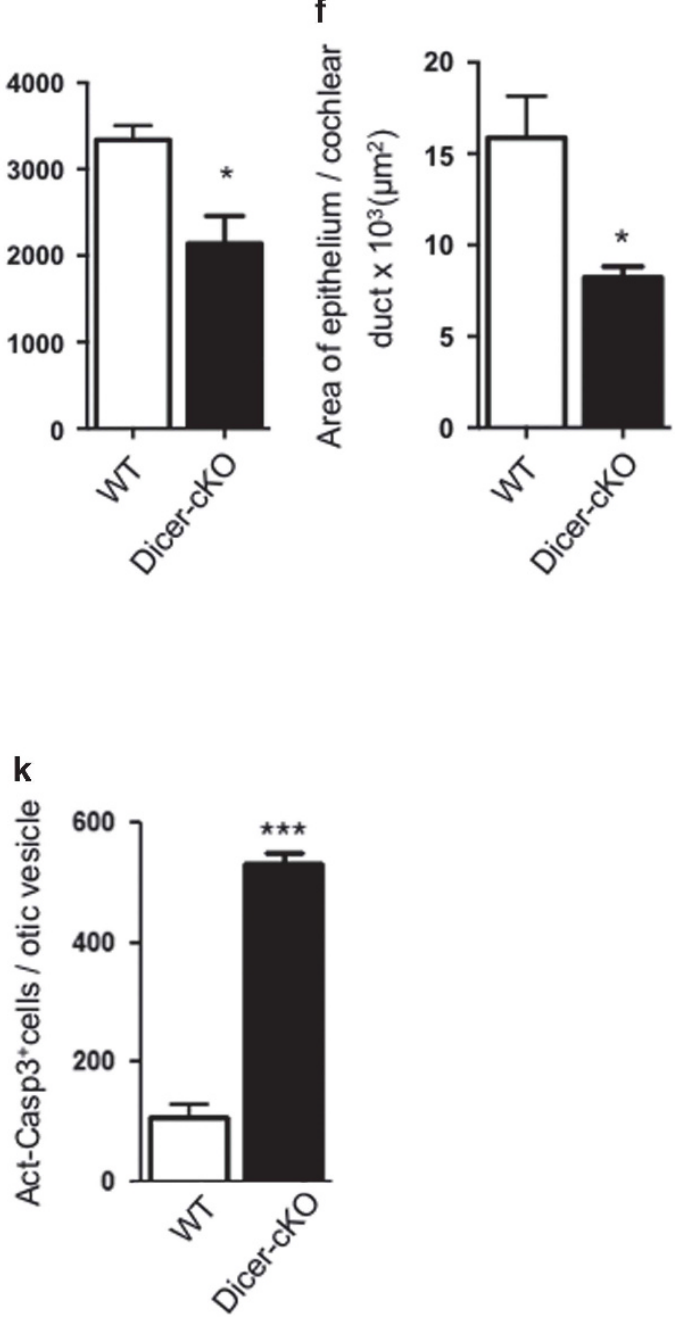

Figure 1 MicroRNA loss induces defects in morphogenesis and cell death. (a, b) In situ hybdridization for miR-183 at the embryonic stage E14.5. miR-183 is present in the cochlear duct (red dotted line) in WT mice cochlea (a) while it is absent in Dicer-cKO cochlea (b). (c, d) Toluidin Blue stained sections of WT (c) and Dicer-cKO littermate (d) cochleae at E14.5. (e, f) Quantifications of cochlear perimeter (e) and area of cochlear epithelium (f) in E14.5 WT and Dicer-cKO sections, followed by a $t$-test analysis $(n=3$ for each genotype). (g, h) Sox2 staining counterstained with DAPI in WT (g) and Dicer-cKO otic (h) vesicle at E11.5. (I, j) Activated Caspase-3 (Act-Casp3) staining (in red) counterstained with DAPI (in blue) at E12.5 in the WT (i) and Dicer-cKO (j) otic vesicle. (k). Quantification of Act-Caspas3+ cells followed by a t-test analysis attests the statistical significance of the increased apoptosis in the Dicer-cKO otic vesicle $(531.8 \pm 16.45 ; n=4)$ in comparison with WT littermate $(107.3 \pm 21.01 ; n=4)$. The dotted line marks the cochlear duct. Data are expressed as mean \pm S.E.M. ${ }^{*} P<0.05 ;{ }^{* \star} P<0.0001$. Scale bars: $50 \mu \mathrm{m}$

transgenic FoxG1-cre mice. ${ }^{28}$ This resulted in Dicer invalidation and in repression of miRNA maturation, specifically in the otocyst. Consistent with inactivation of Dicer, in situ hybridizations revealed decreased levels of multiple miRNAs in Dicer-depleted cochleae, including the highly expressed miR-183 (Figures 1a and $b$ and ${ }^{29}$ ). Dicer-cKO neonates are unable to breath resulting in their death rapidly after birth. ${ }^{28}$

Morphogenetic analysis of the developing inner ear of Dicer-cKO embryos showed that the otic placode invagination occurs normally (data not shown). Accordingly, we observed a well-developed otic vesicle in Dicer-cKO embryos at E11.5 (Figures $1 \mathrm{~g}$ and $\mathrm{h}$ ). Sox2-positive sensory progenitors, delimiting the prosensory domain, were indeed present in equivalent number in WT and Dicer-cKO otic vesicles
(Figures $1 \mathrm{~g}$ and $\mathrm{h}$ ), indicating that the prosensory domain is correctly established. Later during development, Dicer-cKO embryos exhibited an underdeveloped cochlear duct (Figures 1c and d) with reduced coiling as previously described in Pax2-Cre; Dicer flox/flox mice. ${ }^{9}$ In addition, the perimeter of the cochlea and the area of sensory epithelium were significantly smaller in the absence of Dicer as compared with WT at E12.5 (data not shown) and E14.5 (Figures 1e and f). To investigate whether the inner ear morphogenesis defects observed in Dicer-cKO embryos resulted from increased cell death, we immunolabelled inner ear serial sections with anti-activated caspase-3 (Act-Casp3) antibodies. At E12.5, Act-Casp3+ cells were hardly detected in the cochlear duct of wild-type (WT) mice (Figure 1i). In contrast, numerous 

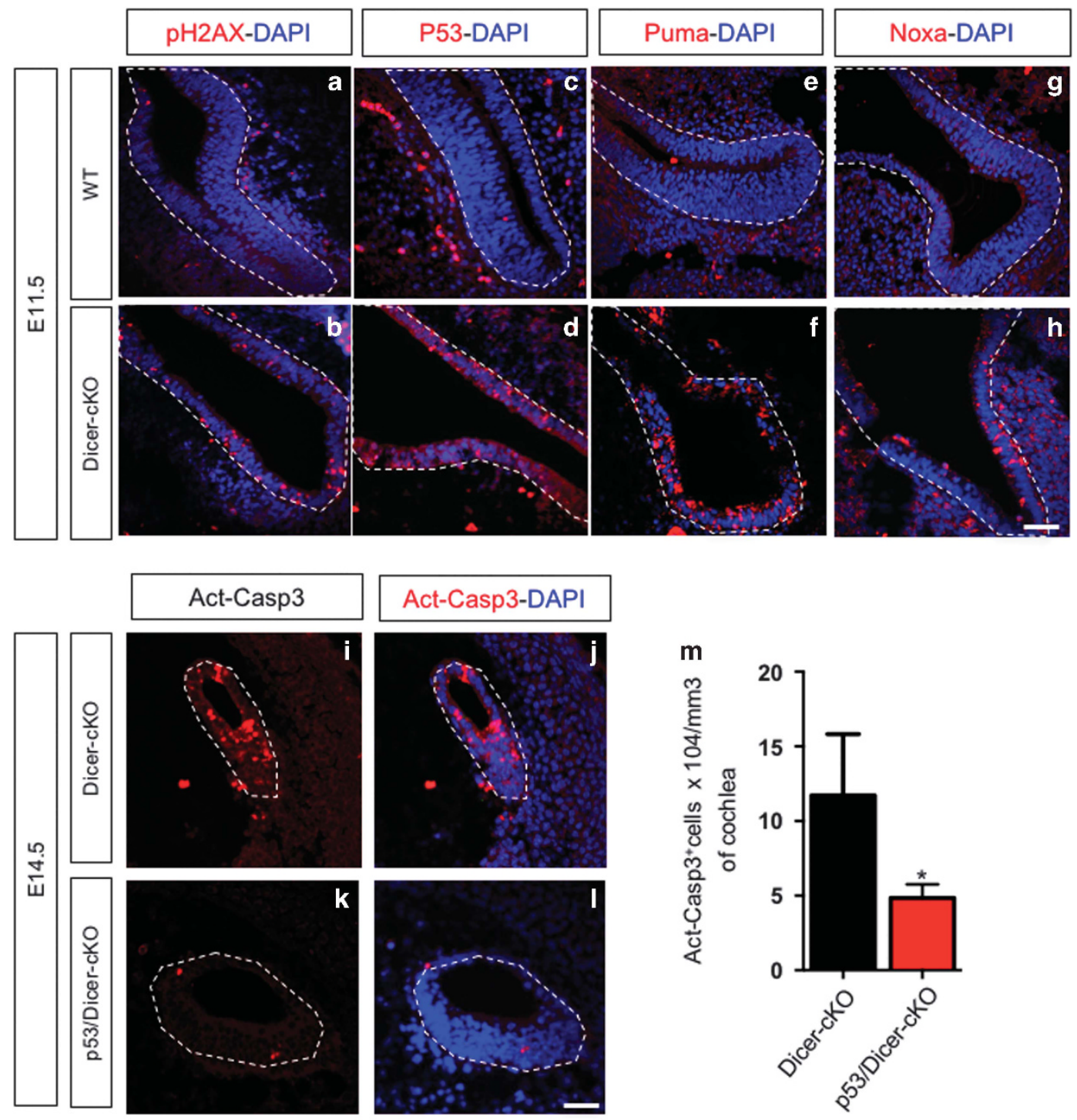

Figure 2 The absence of Dicer induces DNA damage and the activation of the p53 pathway. (a-h) Representative transverse sections of E11.5 cochlear sections from WT (a, $\mathbf{c}, \mathbf{e}, \mathbf{g})$ or Dicer-cKO (b, d, f, h) animals after immunofluorescence counterstained with DAPI in blue. (a, b) phospho-histone H2AX (pH2AX), (c, d) p53, (e, f) Puma, (g, h) Noxa (all in red). (i-l) Immunohistochemistry against activated-caspase-3 (Act-Casp3; in red) in Dicer-cKO (i, j) and p53/Dicer-cKO (k, I) at E14.5 counterstained with DAPI (in blue). The dotted line marks the cochlear duct. $(\mathbf{m})$ Quantification of apoptosis in Dicer-cKO and p53/Dicer-cKO cochlear ducts at E14.5. Data are expressed as mean \pm S.E.M. ${ }^{*}=P<0.05$ (t-test analysis). Scale bars: $50 \mu \mathrm{m}$

Act-Casp3+ cells were detected in the cochlear duct of Dicer-cKO mice (Figure 1j). Quantification of Act-Casp3+ cells revealed a fivefold increase in the number of apoptotic cells within the otic vesicle of Dicer-cKO animals as compared with WT (Figure 1k). A similar increase in apoptosis was seen in the Dicer-cKO cochlea at E14.5 (Figures $2 \mathrm{i}$ and $\mathrm{m}$ ). Thus, the loss of mature miRNAs triggers massive cell death during the early development of the cochlear duct.

The lack of Dicer results in DNA damage and activation of the p53 pathway. We then asked whether loss of Dicer induced DNA damage as previously described. ${ }^{30,31}$ Interestingly, E11.5 Dicer-cKO otic vesicle displayed elevated expression of phospho-histone $\mathrm{H} 2 \mathrm{AX}$ ( $\mathrm{pH} 2 \mathrm{AX}$ ) positive cells, a marker of double-strand DNA breaks (Figures 2a and b). In response to DNA damage, p53 and pro-apoptotic proteins such as NOXA and PUMA are upregulated. ${ }^{32,33}$ To assess if these proteins were involved in the DNA damage response observed in the absence of Dicer, we analyzed their expression by immunohistochemistry. As shown in Figures $2 c-h$, an increase in the expression of these three proteins was observed upon deletion of Dicer in the cochlear duct at E11.5. Together, these results indicated that the absence of Dicer triggers DNA damage associated with an overexpression of p53 and the transcription of its downstream target genes. To further verify the role of p53 pathway in apoptosis caused by Dicer deletion, we bred Dicer-cKO mice with p53 flox/flox mice to generate Dicer-cKO; p53-null mice (called p53/Dicer-cKO) and we found that the number of apoptotic cells was significantly reduced in p53/Dicer-cKO 
otic vesicle as compared with Dicer-cKO embryos (Figures 2i-m). Taken together, these data indicate that p53 pathway is activated after excessive DNA damage induced by Dicer deletion.

Dicer controls prosensory epithelial progenitor proliferation. Another important step of cochlear development consists in the specification of a prosensory area within the ventral part of the developing otocyst and their proliferation rate in order to generate an appropriate number of sensory progenitors. Under physiological conditions, these Sox2expressing cells within the cochlear prosensory epithelium are dividing and become post-mitotic around E13, depending on their position within the longitudinal axis of the cochlea. At this stage, a non-proliferative zone (NPZ) forms inside the cochlear duct. ${ }^{34}$ We first asked whether cell proliferation within the cochlea was disrupted in absence of miRNAs. Time-pregnant females were injected with BrdU at E13.5 and embryos were analyzed at E14.5. We identified an important proliferation within the prosensory domain stained by Sox2 in Dicer-cKO embryos, whereas no obvious proliferating cells are present in the NPZ of WT cochleae (Figure 3a). As abnormal proliferation often results in cell death, ${ }^{35,36}$ we analyzed the presence of BrdU/Act-Casp3-positive cells in the prosensory domain of the cochlea. Indeed, BrdU-positive apoptotic cells were seen in the Sox2 domain (Figure 3a, arrowhead). Interestingly, ongoing cell proliferation in the NPZ seen with Dicer invalidation was p53-independent as co-deletion of Dicer and p53 does not restore the ZNP in E14.5 cochlear duct (Figures $3 b$ and $c$ ). These results indicate that Dicer is necessary to define the NPZ in the cochlea and that its absence leads to a massive proliferation of progenitor cells followed by cell death.

Dicer invalidation interferes with expression of genes involved in inner ear development. We compared expression profiles of protein-coding genes in WT and Dicer-cKO littermate otic vesicles at E12.5 by microarray analysis to identify potential miRNAs target messengers, as previously

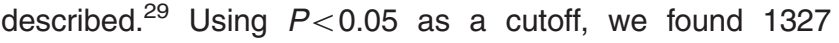
upregulated genes in Dicer-cKO (fold change $\geqslant 1.6$ ) and 877 downregulated genes (fold change $\leqslant-1.6$ ) (Figure 4a). A gene ontology (GO) analysis of upregulated genes in DicercKO revealed a significant enrichment in genes related to DNA damage response, regulation of actin-based motility, p53 signaling and Integrin signaling (Figure $4 \mathrm{~b}$ and c). Interestingly, Integrin signaling pathway has been shown to be involved in inner ear development. ${ }^{37,38}$ Consistently, functions such as Hearing, Cell survival and Growth were reduced in Dicer-cKO as compared with WT (Figure 4b). Taken together these results confirmed the observed phenotype in Dicer-cKO developing inner ear and validate immunolabelings supporting that inactivation of Dicer induces DNA damage and a subsequent p53-dependent apoptosis. Moreover, the integrin pathway was also found to be affected in Dicer-cKO, notably by increased expression of numerous integrins (Figure 4c). Among those, we confirmed by qRTPCR and immunohistochemistry (Figures $5 \mathrm{a}$ and b) that ItgA3 is increased in Dicer-cKO cochleae as compared with WT.
miR-183 targets ITGA3. Because the miR-183 family (that includes miR-96, miR-182 and miR-183) was the main miRNA family identified so far in the early developing otic vesicle, ${ }^{11,15,26}$ we investigated whether those miRs could target ItgA3. Using the MiRanda, TargetScan and PicTar predictive databases, we found a complementarity between seed sequences of miR-183 family members and the 3'UTR of mouse $\operatorname{ltg} A 3$ (Figure $5 \mathrm{c}$ ). To examine whether ItgA3 was a physiological target of miR-183 family, the 3'UTR of ItgA3 was cloned into a reporter vector and luciferase assays were performed in HEK-293T cells transfected with miR-96, miR-182, miR-183 mimics or negative control RNA (negctl). Renilla Luciferase activity of ItgA3 3'UTR plasmid was significantly decreased in the presence of miR-183 but not with miR-96 nor miR-182 (Figure 5d). A mutated form of ItgA3 3'UTR (Figure $5 \mathrm{c}$ ) abolish the negative effect of miR-183 on the luciferase activity, suggesting the specific effect of miR-183 on the 3'UTR of ItgA3 (Figure 5d). Accordingly, in the presence of miR-183 hairpin inhibitor, UB-OC1 cells highly overexpressed ItgA3 (Figure 5e). Taken together, these results indicate that $\operatorname{Ig} A 3$ is a target gene of miR-183.

ItgA3 overexpression decreases cell adhesion and increases proliferation. Having identified ItgA3 as a direct target of miR-183, we next sought to characterize whether ItgA3 overexpression could recapitulate the phenotypic abnormalities observed in early developing otic vesicles and cochlear ducts of Dicer-cKO embryos. ITGA3 overexpression in UB-OC1 cells, (Figures 6a and b) is indeed responsible for increased proliferation (Figure $6 \mathrm{c}$ ). Although $25.8 \pm 3.4 \%$ of GFP-positive cells were Ki67 positive in control-GFP transfected cells, forced expression of ItgA3GFP resulted in a significant increase of Ki67-positive cells among the GFP-positive population $(36.1 \pm 1.9 \%, P<0.05)$ (Figure 6d). Because the ability of cells to interact with their extracellular environment is crucial for most developmental processes including in the inner ear and the integrins are known to be involved in this mechanism, ${ }^{39,40}$ we next sought to determine whether the overexpression of ItgA3 could affect the cell adhesion. When we looked for the involvement of ItgA3 in cell adhesion, we observed significant adhesion alterations on different extracellular matrices. In particular, ItgA3 overexpression in UB-OC1 cells decrease significantly adhesion on fibronectin and laminin (Figures $6 e$ and f). Taken together, these data suggest that overexpressing ItgA3 in cochlear cells induced increased proliferation and decreased cell adhesion, that would lead to decreased cell survival.

\section{Discussion}

Maintaining proper population of prosensory cells that will give rise to $\mathrm{HCs}$ and $\mathrm{SCs}$ in the organ of Corti is essential for inner ear function. The mechanisms through which miRNAs regulate inner ear development have been investigated in different studies. ${ }^{9,29,41}$ However, no data were available concerning miRNA role at early stages of development. Here, by using a mouse model with a conditional removal of Dicer in the otocyst and performing global gene expression profiling from E12.5 inner ears, we discovered an important role for miRNAs during early development of this 
a

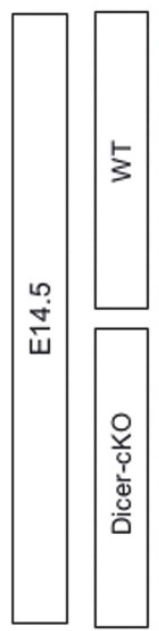

b

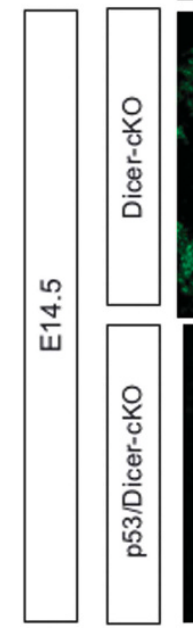

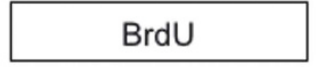
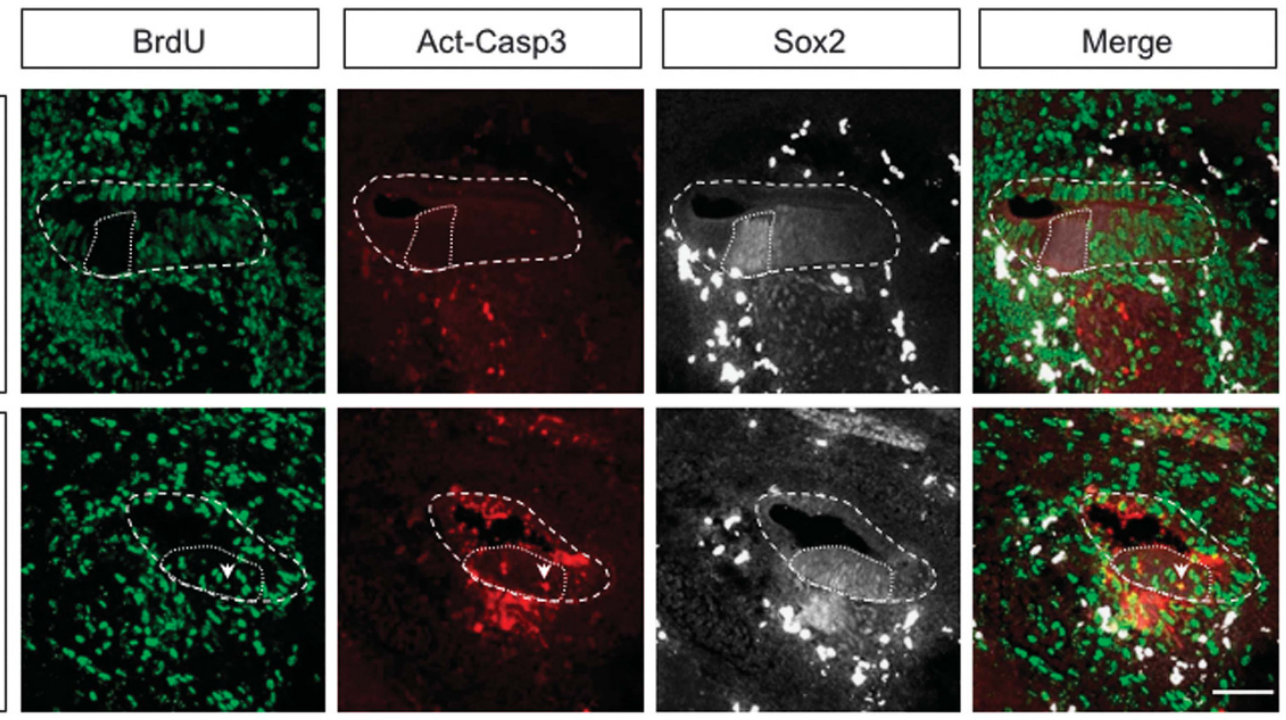

c

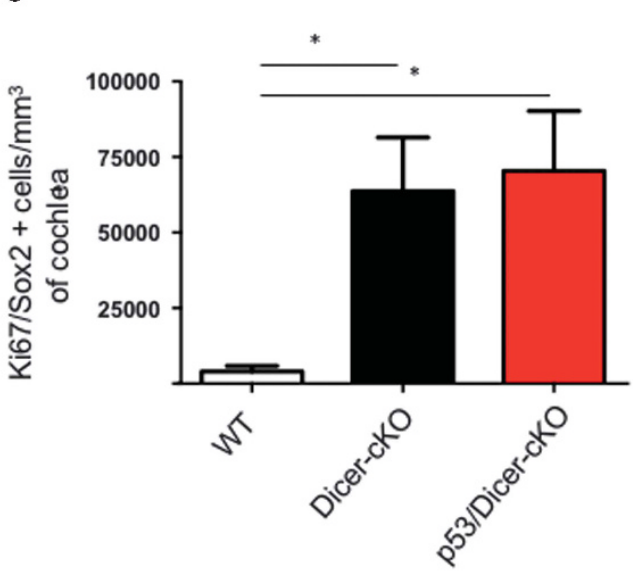

Figure 3 The lack of Dicer induces defects in proliferation of the prosensory cells in the cochlea followed by cell death. Timed pregnant females were injected with BrdU at E13.5. Embryos were analyzed at E14.5 and their cochleae were immunolabeled to analyze the BrdU incorporation within the prosensory domain. (a) BrdU (in green), activatedcaspase-3 (Act-Casp3) (in red), Sox2 (in white) staining in WT and Dicer-cKO. The dotted line marks the cochlear duct. Arrowhead shows a cell double labeled for BrdU and ActCasp3. (b) Ki67 (in green)/Sox2 (in red) double-labeled cochlear sections from E14.5 Dicer-cKO and p53/Dicer-cKO littermate. The quantification followed by an ANOVA analysis (c) attests the statistical significance of the increased proliferation in the Dicer-cKO $(63.726 \pm 35.534 ; n=4)$ and p53/Dicer-cKO cochlea $(70.416 \pm 39.619 ; n=4)$ in comparison with WT littermate $(4.050 \pm 3.688 ; n=4)$. Data are expressed as mean \pm S.E.M. *: $P<0.05$. Scale bars: $50 \mu \mathrm{m}$

organ. The Dicer-cKO embryos showed a defect in the development of inner ear, especially caused by an abnormal proliferation, an increase in DNA damage and p53-mediated apoptosis in the prosensory domain of the cochlea (Figure 7). Among the potential miRNAs/target gene responsible for this phenotype, we identified ItgA3 as a target of miR-183 and observed that the repression of ItgA3 could be a key mechanism in the regulation of cell proliferation in the developing cochlea.

Dicer acts as a key regulator of survival at early stages of inner ear development. In the absence of miRNAs maturation, the otic placode invaginates normally and the otic vesicle presents a normal histological appearance. Moreover, the specification of Sox2-positive prosensory cells occurs normally and the prosensory domain seems correctly established by E11.5. The lack of phenotype following Dicer knockout in early developing otocyst could be due to the delay between Cre-recombinase expression and efficient invalidation of Dicer gene as well as to the long half-lives of Dicer mRNA and protein ${ }^{42,43}$ and thus miRNAs generated during the early developmental phase of inner ear development remain present. Although FoxG1 expression starts as early as $E 9$ in the otocyst, ${ }^{28}$ the decrease in miRNAs levels in the developing inner ear of Dicer-cKO mice was delayed, consistent with the relatively long half-life of miRNAs. ${ }^{44}$ Alternatively, the developmental pattern of expression of miRNAs in the early developing otocyst is not well described 
a

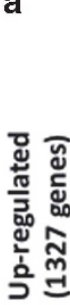

Dicer-cKO

WT
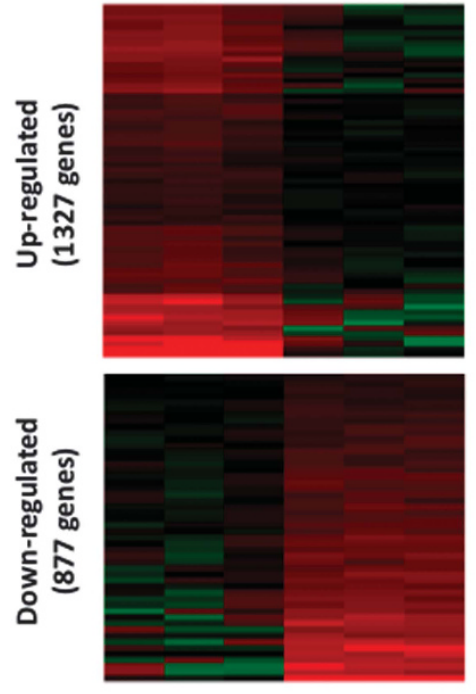

$\log 2$ ratio

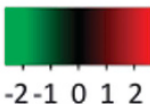

b IPA canonical pathways

DNA damage
Regulation of actin based motility
Death Receptor Signaling
Integrin signaling
P53 Signaling

IPA diseases and functions

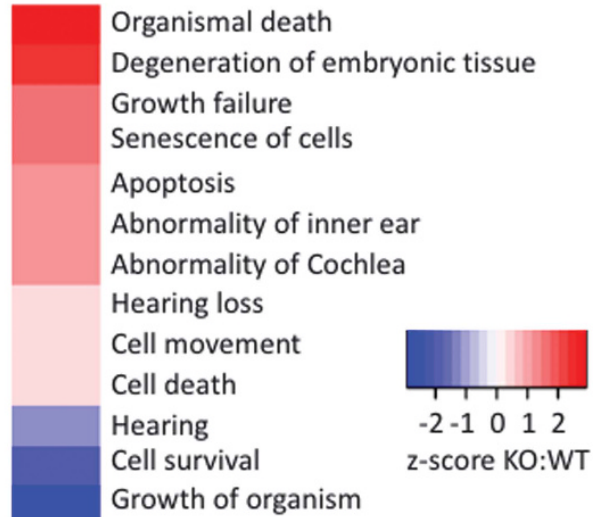

C

\begin{tabular}{ll}
\hline Signaling pathway & Representative up-regulated genes \\
\hline DNA damage & Cdc25c, Gadd45a, Ccnb3, Brca1 \\
\hline Integrin signaling & ItgA1, ItgA3, ItgA7, ItgA8, ItgB3 \\
\hline p53 signaling & Pik3cd, Pik3c2g, Pik3c2a \\
\hline Death receptor signaling & Map3k5, Gas2, Tnfrsf21 \\
\hline
\end{tabular}

Figure 4 Dicer inactivation induces the modulation of expression of several genes involved in inner ear development. Microarray experiment was performed from 3 Dicer-cKO and 3 WT littermate cochleae. We chose differentially expressed genes with $P<0.05$ cutoff. (a) Heatmap representing the log2 fold change of expression intensity per sample and gene. Upregulated genes in Dicer-cKO cochleae are on the top and downregulated genes on the bottom. Each row represents a single gene and each column a single sample. (b) Heatmap representing the $z$-score of the canonical pathways and disease and functions annotations significantly modulated in Dicer-cKO cochleae, calculated using IPA. A positive or negative z-score (red and blue) indicates respectively an up- or a downregulation of the pathway in Dicer-cKO (KO) in comparison with WT littermate. (c) Representative genes identified by the microarray analysis and belonging to canonical pathways found to be upregulated in Dicer-cKO cochleae

and no miRNAs have been identified so far before E9.5 in the inner ear.

Later during the development, our findings indicate that Dicer is essential to preserve otic morphogenesis. These results correlates with what was previously observed. ${ }^{9,22} \mathrm{We}$ investigated which mechanisms were involved in these developmental defects and found a massive DNA damage leading to the activation of p53 apoptotic pathway and finally cell death in the otic vesicle. These results could be explained by a specific regulation of $\mathrm{H} 2 \mathrm{AX}$ expression and genes involved in DNA damage repair by miRNAs. Indeed, studies showed that miRNAs can modulate H2AX expression, as well as its phosphorylation. ${ }^{45,46}$ Therefore, in the absence of mature miRNAs, the expression and phosphorylation of H2AX would activate apoptotic pathways in the otic vesicle. Alternatively, the effects observed might be due to miRNAindependent cell survival function of Dicer, as previously reported. ${ }^{31,47}$ Indeed, Dicer has been shown to process small noncoding RNAs that are necessary for an efficient DNA damage response. In that case, it would explain why we could not identify any specific miRNA with a protective effect against DNA damage (see next paragraph).

DNA damage is followed by a massive apoptotic cell death through, at least partially, a p53-dependent pathway. DNA damage and apoptosis caused by knockdown of Dicer have been reported elsewhere. ${ }^{30,31}$ However, a large number of studies report that stem/progenitor cells are more tolerant to DNA damage than differentiated cells. ${ }^{48,49}$ This suggest that early otic progenitors do not share those characteristic features with stem cells. However, as differentiation progresses during the development of the inner ear, progenitors may become less sensitive to DNA damage, since Sox2positive progenitor cells are well present in the developing otic vesicle of Dicer-cKO mice. The number of these cells is even elevated in Dicer-cKO compared with WT and this increase is p53-independent. 
a

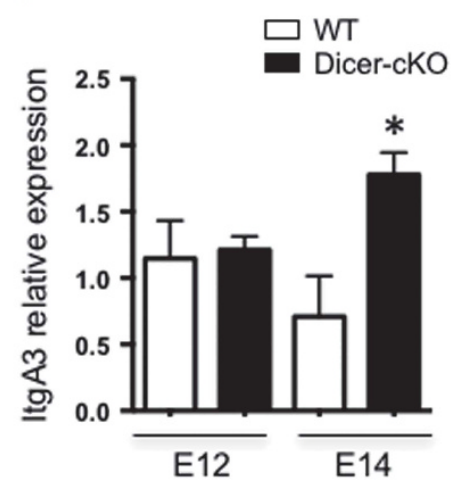

b
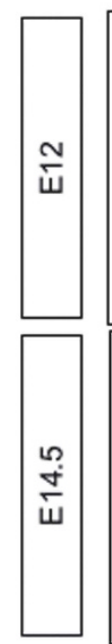
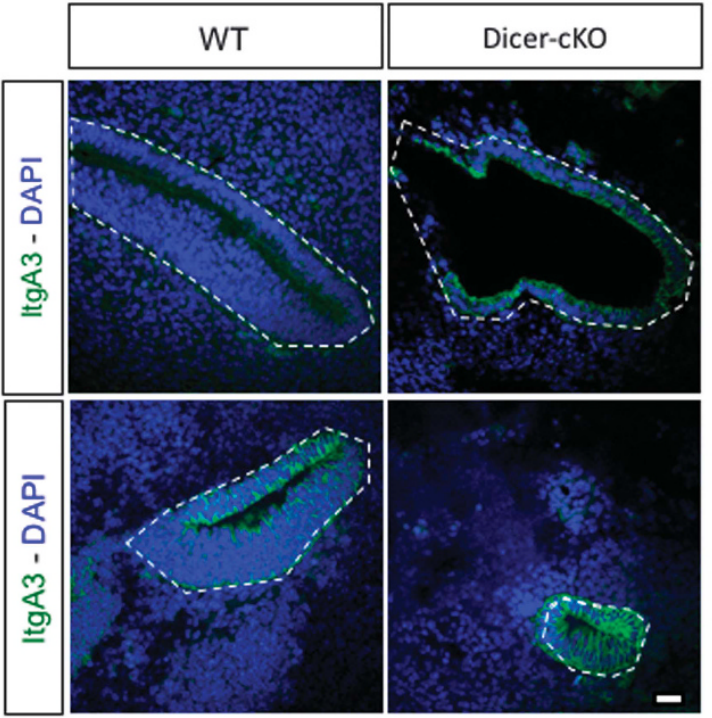

d

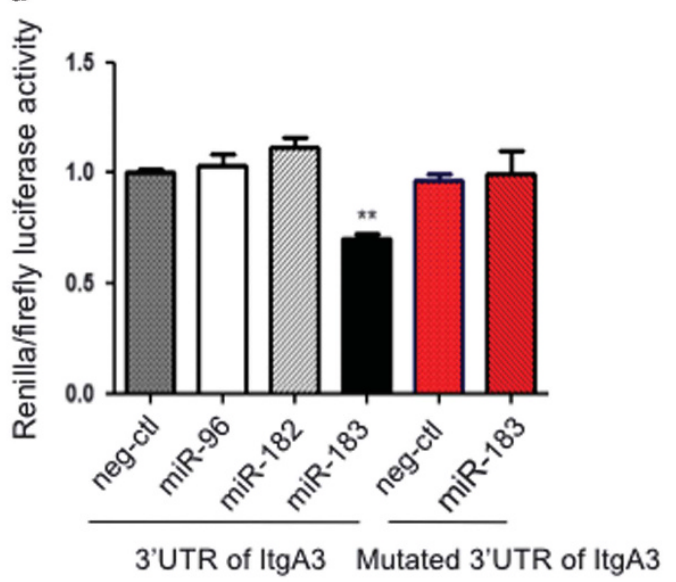

3'UTR of ItgA3 Mutated 3'UTR of ItgA3
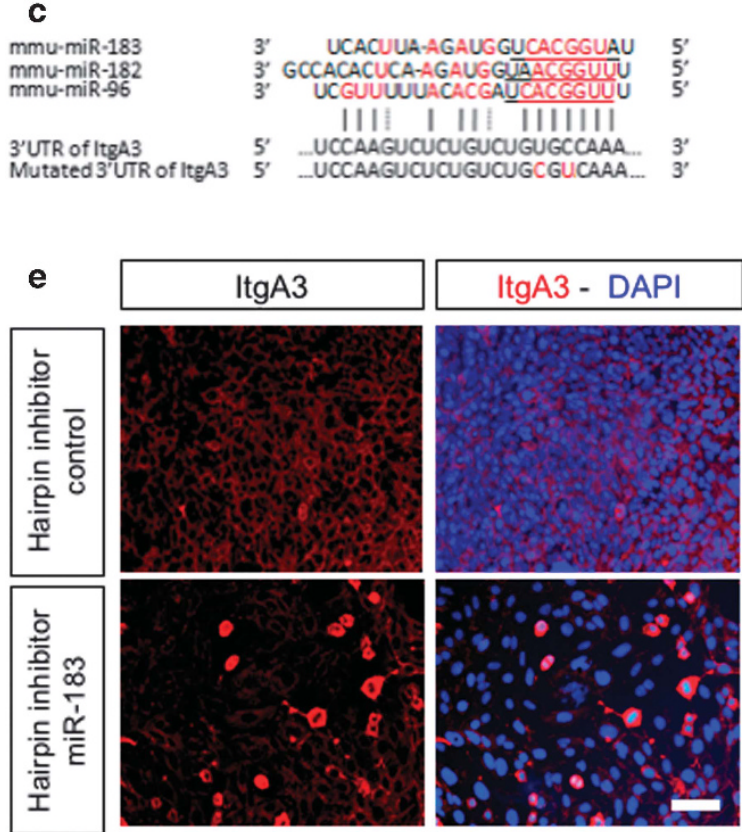

Figure 5 Integrin alpha 3 (ItgA3) is targeted by miR-183 expressed in the cochlea. (a) Expression level of ItgA3 determined by qRT-PCR on E12.5 and E14.5 cochleae. Gene expression was normalized on Gapdh level and the results are shown as fold change relative to WT at E12.5 (Data represent the average of at least three independent experiments \pm S.E.M.). (b) Immunolabellings for ItgA3 (in green) counterstained with DAPI (in blue) at E12.5 and E14.5 in Dicer-cKO and WT littermate cochleae. ItgA3, weakly expressed in WTembryonic cochleae, is overexpressed in Dicer-cKO cochlear ducts. The dotted line marks the cochlear duct. (c) Predicted base pairing of mature mmu-miR-96, $-182,-183$ and ItgA3 3'UTR are illustrated in red. Seed sequence of miRNAs are underlined. Mutated binding site in the 3'UTR of ItgA3 are also indicated in red. (d) Luciferase assay in HEK-293T cells co-transfected with vectors coding either the WTor Mutated 3'UTR of ltgA3and corresponding miRNA. Data are expressed as mean \pm S.E.M. of at least three independent experiments (**: $P<0.01$ ). (e) ItgA3 staining (in red) counterstained with DAPI (in blue) of transfected UB-OC1 cells (an otocyst-derived cell line) with miR-183 hairpin inhibitors or control hairpin inhibitors. Scale bars: $50 \mu \mathrm{m}$

miR-183 fine tunes ItgA3 expression to regulate cell proliferation but not apoptosis. For a better understanding of the mechanisms involved in the phenotype observed at early stages of inner ear development, we performed high throughput transcriptomic analyses from WT or Dicer-cKO cochleae at E12.5. Functional pathways analyses revealed that signaling pathways related to apoptosis and response to DNA damage were upregulated in Dicer-cKO confirming our phenotype. In addition, these analyses showed that Integrin signaling pathway was upregulated in Dicer-cKO mice. Among this, we found that ItgA3 was the only gene targeted by miR-183 cluster, the only miRNAs identified so far in the 
early developing otocyst. ${ }^{15}$ Using luciferase assays, our results showed that only miR-183 had the ability to inhibit ItgA3 expression.

The Integrin family of extracellular matrix receptors is known to be regulated by specific miRNAs. ${ }^{50}$ During organogenesis, cell-cell or cell and extracellular matrix interactions are very important to ensure proper organ development, including the inner ear. Indeed, it was shown that ItgA3 is expressed in the early otocyst and that its levels decline in the prosensory area at $\mathrm{E} 12.5,{ }^{51}$ suggesting a potential role in early inner ear development. Therefore, the abnormal level of ItgA3 present at E12.5 in Dicer-cKO could affect the development of inner ear by modulating these interactions. In addition, elevated integrin expression, in the absence of the appropriate ligands, has been shown to promote apoptosis. ${ }^{52}$ Based on these observations, accumulation of ItgA3 in Dicer-cKO otocysts could explain the massive apoptosis observed at early stages of inner ear development. However, we failed to confirm this hypothesis using UB-OC1 cultures treated with ItgA3 or miR-183 inhibitors (data not shown). Therefore, according to our results, DNA damage and apoptosis caused by depletion of Dicer are not linked to miR-183/ltgA3. However, the transfection efficiency of UB-OC1 with the vector overexpressing ItgA3 is $\sim 50 \%$, and our bioassay may not be sensitive enough to detect if an overexpression of $\operatorname{ltg} A 3$ could induce cell death if only half of the cells overexpress the protein. It is also important to notice that UB-OC1 cells are immortalized and could be less sensitive to apoptosis than otic progenitors in the developing inner ear. Moreover, UB-OC1 cells are derived from otic progenitors of E13 mouse embryos but we observed that $\operatorname{lgA} 3$ seems to be regulated by miRNAs at earlier stages of inner ear development (E12.5). Thus, UBOC1 cells could be less sensitive to ItgA3 overexpression than the otic progenitors because they are not in the same 'time window' of the inner ear development. Finally, it is possible that other genes regulated by other miRNA cluster are involved in the apoptosis observed in Dicer-cKO mice. In this case, the overexpression of $\operatorname{IgA} 3$ or the inhibition of miR-183 family could not be sufficient to induce apoptosis. Indeed, $\mathrm{GO}$ analyses of the genes modulated by Dicer inactivation identified other genes involved in apoptosis. However, although we cannot exclude that other miRNAs/specific targets could have a role during this early developmental period, it is more likely that the absence of Dicer in highly proliferating cells is linked to replication-associated DNA damage as recently shown in the developing cerebellum. ${ }^{31}$

Integrin signaling is also known to be involved in cell proliferation $^{53,54}$ and could thus be linked to the defective cell cycle arrest of Sox2 progenitors observed in Dicer-cKO animals. Consistently, ItgA3 overexpression induces ongoing proliferation of UB-OC1 cells cultured in non-proliferative conditions. Moreover, a study showed an anti-metastatic effect of miR-183 by repressing ITGB1 gene, confirming that miRNAs can regulate the abnormal proliferation by targeting integrins. ${ }^{55}$ Taken together, the present findings indicate that miR-183 has a critical role in early inner ear development by modulating the expression of ItgA3 and guarantees a normal development of the cochlear prosensory area (Figure 7). Interestingly, in Alport syndrome, a genetic disorder mainly due to defect in type IV collagen and characterized by kidney disease and neurosensory hearing loss, an overexpression of $\operatorname{Itg} \mathrm{A} 3$ is observed. ${ }^{56}$ Whether those patients present also a deficit in miR-183 remains to be demonstrated.

In conclusion, our work emphasizes that Dicer is crucial in regulating mechanisms that control prosensory domain growth in the mammalian inner ear using probably both canonical (miRNAs) and non-canonical RNAi. These findings point out new avenues for $\mathrm{HC}$ regeneration that prerequisite the identification of molecular pathways controlling prosensory domain growth.

\section{Material and Methods}

Mouse strains and BrdU preparation. Dicer floxfflox mice ${ }^{27}$ were bred, as previously described, ${ }^{7}$ to FoxG1-Cre mice ${ }^{28}$ in a mixed background (C57bl/6, 129SvJae) to obtain FoxG1-Cre/+; Dicer flox/flox embryos (Dicer-cKO) and FoxG1 +/+; Dicer flox/flox (hereafter referred as wild-type, WT). To generate p53/Dicer-cKO embryos, Dicer flox/flox mice were first crossed with p53 flox/flox mice (Jackson laboratories, gracious gift from Dr. Santamaria, CNIO Madrid) to generate Dicer flox/+; p53 flox/+. Then, Dicer flox/+; p53 flox/+ were mated together to generate Dicer flox/flox, p53 flox/flox mice. Mating of a Dicer flox/flox, p53 flox/flox mouse with a FoxG1-Cre/+; Dicer flox/+ yield to FoxG1-Cre/+; Dicer flox/+; p53 flox/+ progeny. Finally, these mice were mated together to produce FoxG1-Cre/t; Dicer flox/flox; p53 flox/flox embryos (p53/Dicer-cKO). Littermates without Cre were used as controls. Genotyping was carried out on genomic DNA derived from adult and embryonic tail using the established PCR protocols for the FoxG1-Cre allele ${ }^{57}$ and for Dicer flox allele. ${ }^{58}$ p53 alleles were amplified with the primer pair: $5^{\prime}$ GGTTAA ACCCAGCTTGACCA3' and 5'GGAGGCAGAGACAGTTGGAG3', amplifying a $270 \mathrm{bp}$ fragment in wild-type (WT) and a $390 \mathrm{bp}$ fragment in p53 flox animals.

BrdU (Sigma-Aldrich, Overijse, Belgium) was dissolved in $0.9 \% \mathrm{NaCl}$ and $0.007 \mathrm{M}$ $\mathrm{NaOH}$, and administrated at $100 \mathrm{mg} / \mathrm{kg}$ body weight by i.p. to time-pregnant females at E13.5. Embryos were collected at E14.5. All animals were taken care of in accordance with the declaration of Helsinki and following the guidelines of the Belgian ministry of agriculture in agreement with EC laboratory animal care and use regulation (86/609/CEE, CE of J no. L358, 18 December 1986).

\section{Imaging}

Tissue preparation: Embryos were collected from time-pregnant females at E11.5; E12, E12.5; E14.5 taking the morning that vaginal plug was observed as E0.5. Embryo's head were fixed in paraformaldehyde 4\% (PFA 4\%) for $6 \mathrm{~h}$ (for immunohistochemistry) or overnight (for in situ hybridization) at $4{ }^{\circ} \mathrm{C}$ and immersed into sucrose $20 \%$ overnight then embedded in gelatin mixture containing $7.5 \%$ of gelatin and $15 \%$ of sucrose dissolved in PBS $1 \mathrm{M}$. The heads were then cryosectioned at $14 \mu \mathrm{m}$ and placed on SuperFrost plus slides (VWR International) for analyses.

Toluidine blue staining: Head sections at E14.5 were immersed for $1 \mathrm{~min}$ in toluidine blue solution (2 $\mathrm{g} / \mathrm{l}$ of toluidine blue in Walpole's buffer containing $27 \mathrm{~g} / \mathrm{l}$ sodium acetate, $1.2 \%$ acetic acid, $\mathrm{pH}$ 7.4). Then, the sections were washed twice in Walpole's buffer for $5 \mathrm{~min}$. Finally, the coloration was fixed with $50 \mathrm{~g} / \mathrm{l}$ ammonium molybdate solution before mounting in Safe Mount (VWR international).

Immunohistochemistry. Head sections were first heated at $94.5^{\circ} \mathrm{C}$ in citric acid based antigen retrieval solution for $15 \mathrm{~min}$ (Dako, Glostrup, Belgium) and then blocked for 30 min with gelatin $0.25 \%$-Triton X-100 0.3\% (Sigma-Aldrich) in PBS $1 \mathrm{M}$ at room temperature. The primary antibodies were diluted in the same solution and incubated overnight at $4{ }^{\circ} \mathrm{C}$. The following primary antibodies were used in various combinations: anti-active Caspase-3 (Rabbit, 1/500, Promega Benelux, Leiden, The Netherlands), anti-Ki67 (Rabbit, 1/500, Cell marque, Rocklin, CA, Dallas, TX, USA), anti-Sox2, (Goat, 1/100, Santa Cruz Biotechnology, Dallas, TX, USA), anti-Betalll-tubulin (Tuj1; Rabbit, 1/500, Covance, Los Angeles, CA, USA), anti-pH2AX (Rabbit, 1/250, Cell signaling, Danvers, MA, USA), anti-p53 (Mouse, 1/100, Cell signaling), anti-Puma, (Rabbit, 1/100, Abcam, Cambridge, UK), antiNoxa, (Rabbit, 1/100, Abcam, UK), anti-BrdU (Rat 1/500, AbD Serotec, Raleigh, NC, USA), anti-ltgA3 (Rabbit, 1/100, a gift from R Hynes, HHMI, MIT, Cambridge, USA). After PBS washes, Donkey anti-mouse/rabbit or goat secondary antibodies conjugated with FITC, RRX or Cy5 (1/1000, Invitrogen, Merelbeke, Belgium) were used. Sections were then mounted in Vectashield containing DAPI (Hard Set 
a

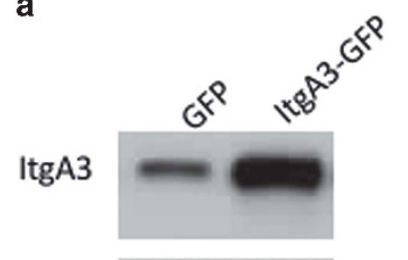

Actin

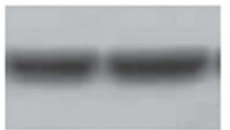

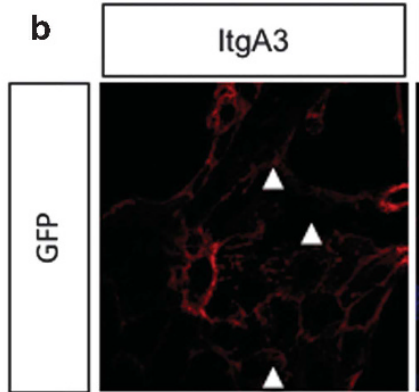
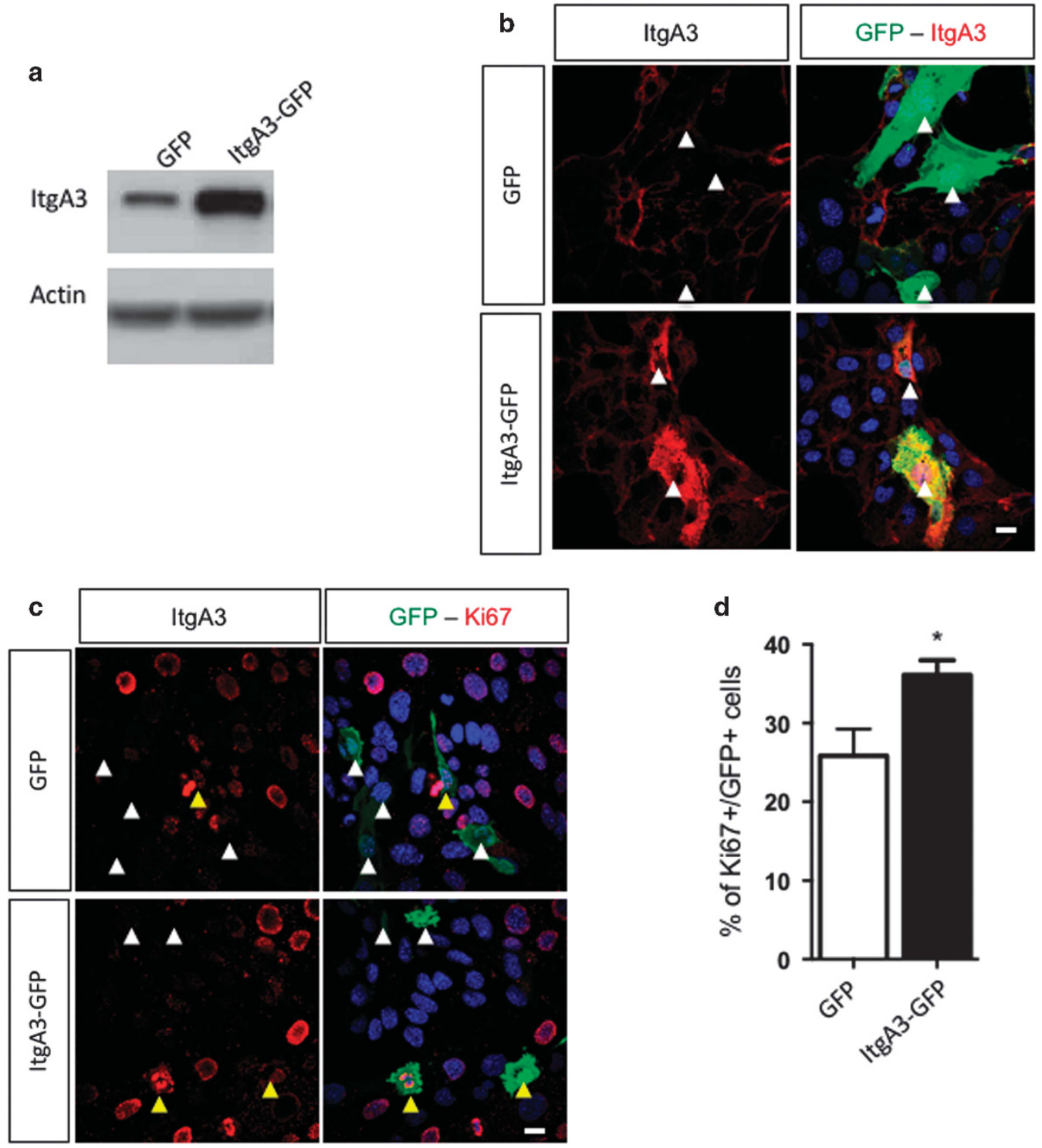

GFP - Ki67
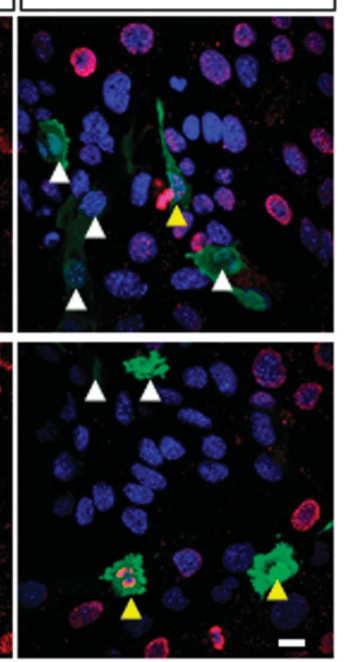

d

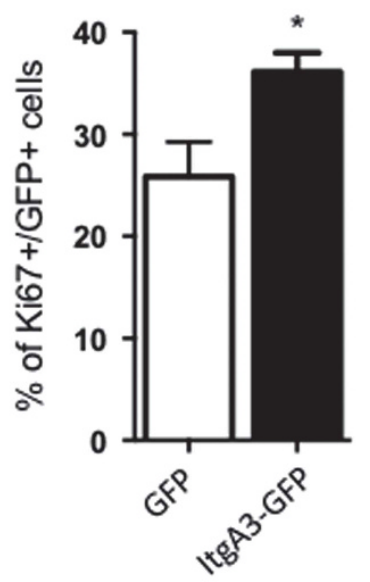

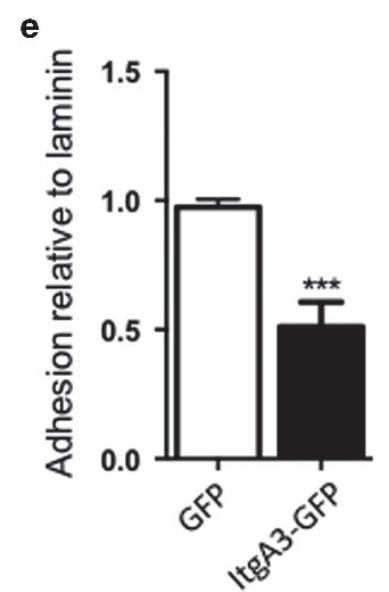

f

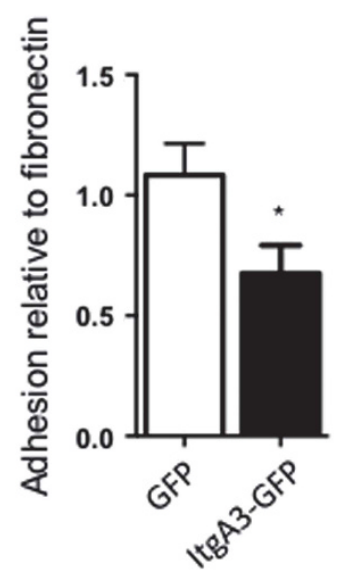


Mounting Medium, Vector laboratories, Burlingame, CA, USA) and examined with a confocal microscope (NIKON A1, Brussels, Belgium).

To perform BrdU detection, DNA was denaturated with $2 \mathrm{~N} \mathrm{HCl}$ for 30 min at $37^{\circ} \mathrm{C}$ followed by $0.1 \mathrm{M}$ borate buffer $\mathrm{pH} 8.5$ for $20 \mathrm{~min}$. Then, the immunofluorescence was performed as previously described.

In situ hybridization: miRNA in situ hybridizations were performed on frozen sections of inner ear with 3'-digoxigeninlabeled LNA antisense probes (Eurogentec, Seraing, Belgium) to mouse miR-183 as previously described. ${ }^{15}$ In brief, the cryosections were fixed in $4 \%$ PFA and treated with $0.25 \%$ acetic anhydride in $0.1 \mathrm{M}$ triethanolamine. The sections were then prehybridized for $2 \mathrm{~h}$ with $50 \%$ formamide, $5 \times$ sodium saline citrate buffer and citric acid to $\mathrm{pH} 6,1 \%$ sodium dodecyl sulfate (SDS) and $500 \mu \mathrm{g} / \mathrm{ml}$ yeast RNA (hybridization cocktail, $50 \%$ formamide, Lucron bioproducts, Sint-Martens-Latem, Belgium). Probe ( $30 \mathrm{~nm}$, final) was added to fresh hybridization cocktail, and hybridization was performed overnight at $50^{\circ} \mathrm{C}$. Hybridized sections were then washed and treated for $1 \mathrm{~h}$ at RT in buffer $\mathrm{B} 1$ (150 mM NaCl, $100 \mathrm{mM}$ Tris, pH 7.4)+buffer B2 (10\% normal goat serum) followed by overnight incubation at $4{ }^{\circ} \mathrm{C}$ with alkaline phosphatase (AP)-labeled antidigoxigenin antibody (1:2000; Roche Applied science, Brussels, Belgium) in buffer B2. After extensive washes, sections were exposed to the substrate for AP, nitroblue tetrazolium, and 5-bromo-4-chloro-3-indoyl phosphate (NBT/BCIP; Sigma-Aldrich, St. Louis, MO, USA). Reaction was blocked by washes with PBS (pH 5.5), followed by postfixation in 4\% PFA for 20 min finish with milliQ water rinses. Slides were coverslipped with Aquamount.

Cell adhesion assay. UB-OC1 cells, an immortalized cell line from mouse cochlear epithelium at E13.5, ${ }^{59}$ (2.10 cells/well) (gift from Pr Matthew Holley) were seeded in 96-well plates coated with laminin (10 $\mu \mathrm{g} / \mathrm{ml}$, Sigma-Aldrich) and cultured in MEM (Lonza, Belgium) supplemented with 10\% Fetal bovine serum (FBS, Lonza, Verviers, Belgium) at $33{ }^{\circ} \mathrm{C}$ in the presence of $\gamma$-interferon as previously described. Twenty-four hours later, the cells were transfected using Transit-X2 reagent (Mirus) with $1 \mu \mathrm{g}$ of expression plasmid constructed by cloning ItgA3 coding sequence into pCAGGs-IRES-GFP vector (ItGA3-GFP) or empty vector (GFP) according to the manufacturer's instructions. After $48 \mathrm{~h}$, attached cells were stained with crystal violet $(0.5 \%$ crystal violet in $20 \%$ methanol) for $5 \mathrm{~min}$. Then, the cells were washed, lysed and the incorporated dye was measured by reading the absorbance at $560 \mathrm{~nm}$. Student $t$-tests were used for comparisons. Values are given as mean \pm S.E.M., with ' $n$ ' representing the number of independent experiment analyzed per condition.

Cell counting. To quantify the active Caspase-3 positive cells, nine sections were photographed and immunopositive cells were counted with Image $\mathrm{J}$ software. The whole cochlear duct was Z-scanned using the $\times 40$ objective and the composite of the Z-stack images was analyzed for each $14 \mu \mathrm{m}$ thick section. On every third section throughout the cochlear duct, total number of positive cells was evaluated. Counts from each section were added and multiplied by 3 to obtain the total number of positive cells per cochlear duct. For measurements of cochlear volume, the outlines of the cochlear duct were traced and cross-sectional areas measured (using ImageJ) on every second serial section. Student's $t$-tests were used for comparisons (GraphPad Software). Values are given as mean \pm S.E.M., with ' $n$ ' representing the number of ear analyzed per condition.

Dual luciferase assay. HEK-293T cells were seeded in 24-well plates, cultured in DMEM supplemented with 10\% FBS and used at $75 \%$ confluence. The cells were transfected using Dharmafect (Thermo Scientific, Dharmacon, Lafayette, LA, USA) with $200 \mathrm{ng}$ miRIDIAN miRNA mimics miR-96, miR-182 or miR-183 (Thermo Scientific, Waltham, MA, USA) and incubated $24 \mathrm{~h}$ at $37^{\circ} \mathrm{C}$. Then, medium was removed from wells and cells in each well were transfected with X-tremeGENE 9 DNA transfection reagent (Sigma-Aldrich) with $1 \mu \mathrm{g}$ psiCheck-2 containing the $3^{\prime} U T R$ of ItgA3 according to the manufacturer's instructions. Negative controls were used by transfecting the miRIDIAN miRNA Mimic Negative Control \#1 (Thermo
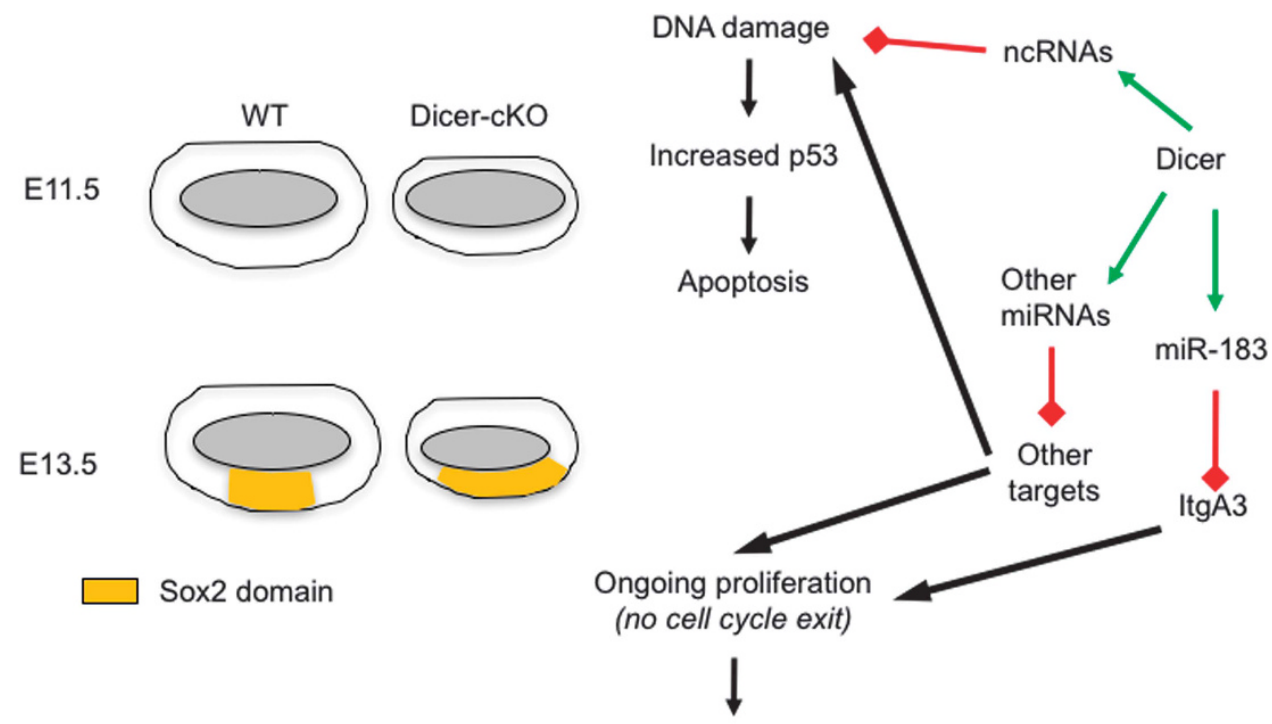

Enlarged Sox2 domain

Figure 7 Summary diagram illustrating how Dicer and miR-183 control cell proliferation and survival partially through ItgA3 signaling pathway in the developing otic vesicle

Figure 6 ItgA3 overexpression increases proliferation and decreases cell adhesion. (a) Representative western blotting of ItgA3 expression level in transfected UB-OC1 cells with ItgA3-GFP or control-GFP plasmid. (b) Immunostaining against ItgA3 (in red) shows the upregulation of ItgA3 2 days after ItgA3-GFP plasmid transfection (GFP-positive cells illustrating in green; white arrowhead). (c) Immunostaining against Ki67 (in red) shows the increase of proliferation 2 days after ItgA3-GFP or control-GFP (green) plasmid transfection (Yellow arrows point Ki67-positive transfected cells and white arrows point KI67 negative transfected cells). (d) Ki67-GFP-positive cells quantification $48 \mathrm{~h}$ after transfection of UB-OC1 with control-GFP $(25.84 \pm 5.92 ; n \leqslant 3)$ or ItgA3-GFP $(36.11 \pm 4.02 ; n \leqslant 3)$ plasmids (t-test analysis, $\left.{ }^{*}: P<0.05\right)$. (e, f) Transfected UB-OC1 cells with ItgA3-GFP without the 3'UTR or control-GFP plasmid were plated onto laminin (d) or fibronectin substrate (e). Cell adhesion was quantified $2 \mathrm{~h}$ after plating on specific substrate. The quantification has been performed on three independent experiments. Data are expressed as mean \pm S.E.M. ${ }^{*}=P<0.05 ;{ }^{* * *}=P<0.001$. Scale bar: $10 \mu \mathrm{m}$ 
Scientific) or with the psiCheck-2 containing the 3'UTR of ItgA3 with point mutations in the seed sequence for miR-183 (uccaagucucugucugGgUcaaa). Cells were incubated $48 \mathrm{~h}$ at $37^{\circ} \mathrm{C}$. Then, the firefly and renilla luciferase activities were measured using the Dual Luciferase Reporter Assay System kit (Promega, Leiden, the Netherland) and Lumat LB 9507 luminometer (Berthold Technologies, Vilvoorde, Belgium). Firefly Luciferase activity was reported to Renilla Luciferase activity to normalize on the transfection efficiency. All experiments were performed in triplicate and repeated at least three times. Values are given as mean \pm S.E.M. from three independent experiments. Data were analyzed with ANOVA and Dunnet's post hoc analysis using GraphPad In Stat software.

Microarray. The cochlea of three individual E12.5 Dicer-cKO or WT littermate mouse embryos were collected and preserved in RNAlater (Ambion, Austin, TX, USA) as previously described. ${ }^{29}$ The tissues were handled by Miltenyi Biotec (Leiden, The Netherlands) for microarray processing and analysis using Agilent Whole Mouse Genome Oligo Microarrays. The raw intensity data were transformed to log2 and subjected to quantile normalization. The comparison between DicercKO and WT cochlea tissue was performed by two-group $t$-test for independent measurements, $n_{\text {Dicer-cko }}=3, n_{\text {wt }}=3$, Welch approximation for equal variance, $P$. values determined based on distribution, $P$-value adjustment for multiple testing using FDR, according to Benjamin Hochberg.

$\mathrm{GO}$ and functional analyses of the differentially regulated genes were performed using Ingenuity Pathway Analysis (IPA; www.qiagen.com/ingenuity; QIAGEN, Venlo, The Netherlands). Genes with their differential expression value (log ratio) were submitted in IPA, allowing the software to calculate the $z$-score, a statistical measure of correlation between relationship direction and gene expression. Therefore, we were able to determine if the functions represented by the genes were up- or downregulated by the miRNAs.

RT-qPCR. Tissue samples from inner ears of E12.5 and E14.5 embryos were homogenized in $1 \mathrm{ml}$ of TRIZOL reagent (Sigma-Aldrich) (per 50-100 mg of tissue) using a sterile plastic homogenizer. A total of $0.2 \mathrm{ml}$ of Chloroform (Sigma-Aldrich) was added and tubes were vortexed and centrifuged. The aqueous phase containing RNA was isolated. RNA was then precipitated with $500 \mu$ isopropano (Sigma-Aldrich) and washed with $1 \mathrm{ml} 70 \%$ ethanol. The RNA pellet was dissolved in DEPC-treated water. For each retro-transcription, $500 \mathrm{ng}$ of purified RNA was used to synthesize cDNA with superscript III DNA polymerase (Roche, Brussels, Belgium). Real-time PCR was carried out using SYBR green master mix (Roche), $1 \mu \mathrm{l}$ of retrotranscribed cDNA and specific primers sets for $\operatorname{ltg} A 3$ in a light cycler (Applied Biosystems, by Life technologies, Merelbeke, Belgium). Transcript levels were normalized on Gapdh expression.

Western blotting. Transfected UB-OC1 cells with GFP or ItgA3-GFP were treated on ice with a lysis solution $(50 \mathrm{~mm}$ Tris $\mathrm{HCl}, \mathrm{pH} 7.4,1 \%$ Triton X-100, $150 \mathrm{mM} \mathrm{NaCl}, 10 \mathrm{mM} \mathrm{NaF}, 1 \mathrm{mM} \mathrm{Na} \mathrm{VO}_{4}$ and protease inhibitors (Protease Inhibitor Cocktail Tablets, Roche)). Protein concentration was determined using Bradford method. Then, $30 \mu \mathrm{g}$ of protein lysates were separated by $10 \%$ SDSpolyacrylamide gel electrophoresis and transferred on PVDF membranes (Millipore, Overijse, Belgium). The membrane was blocked with $5 \%$ dried fat-free milk in TBSTween $0.1 \%$ (TTBS) for $1 \mathrm{~h}$ at room temperature. Then, the membranes were incubated overnight at $4{ }^{\circ} \mathrm{C}$ with the following antibodies diluted in the same solution: ItgA3 (Rabbit, 1/2000, a gift from R. Hynes, HHMI, MIT, Cambridge, USA); B-actin (Mouse, 1/25000, Sigma-Aldrich). After TTBS washing, membranes were incubated with the appropriate horseradish peroxidase-conjugated secondary antibody $(1 / 5000, A b c a m)$ for $2 \mathrm{~h}$ at room temperature. Protein expression was detected by enhanced chemiluminescence (ECL, GE Healthcare, Machelen, Belgium). ItgA3 protein expression was normalized on $\beta$-Actin.

\section{Conflict of Interest}

The authors declare no conflict of interest.

Acknowledgements. We thank JM Hébert and M Merkenschlager for sharing transgenic mouse lines; $R$ Hynes for providing ItgA3 antibody. We thank the GIGAImaging and Flow Cytometry platform for technical support. LN and BM are Research Associate and Senior Research Associate from the Belgian National Funds for Scientific Research (FRS- FNRS), respectively. BM is funded by grants from the FRSFNRS, the Fonds Léon Fredericq, the Fondation Médicale Reine Elisabeth and the Belgian Science Policy (IAP-VII network P7/07).
1. Lai EC. Micro RNAs are complementary to $3^{\prime}$ UTR sequence motifs that mediate negative post-transcriptional regulation. Nat Genet 2002; 30: 363-364.

2. Lewis BP, Burge $C B$, Bartel DP. Conserved seed pairing, often flanked by adenosines, indicates that thousands of human genes are microRNA targets. Cell 2005; 120: 15-20.

3. Huang $Y$, Zou $Q$, Song $H$, Song $F$, Wang $L$, Zhang $G$ et al. A study of miRNAs targets prediction and experimental validation. Protein Cell 2010; 1: 979-986.

4. Yan X, Chao T, Tu K, Zhang $Y$, Xie L, Gong $Y$ et al. Improving the prediction of human microRNA target genes by using ensemble algorithm. FEBS Lett 2007; 581: 1587-1593.

5. Elkan-Miller T, Ulitsky I, Hertzano R, Rudnicki A, Dror AA, Lenz DR et al. Integration of transcriptomics, proteomics, and microRNA analyses reveals novel microRNA regulation of targets in the mammalian inner ear. PLOS ONE 2011; 6: e18195.

6. Chen JF, Mandel EM, Thomson JM, Wu Q, Callis TE, Hammond SM et al. The role of microRNA-1 and microRNA-133 in skeletal muscle proliferation and differentiation. Nat Genet 2006; 38: 228-233.

7. Volvert ML, Prevot PP, Close P, Laguesse S, Pirotte S, Hemphill J et al. MicroRNA targeting of CoREST controls polarization of migrating cortical neurons. Cell Rep 2014; 7: 1168-1183.

8. Callis TE, Chen JF, Wang DZ. MicroRNAs in skeletal and cardiac muscle development. DNA Cell Biol 2007; 26: 219-225.

9. Soukup GA, Fritzsch B, Pierce ML, Weston MD, Jahan I, McManus MT et al. Residual microRNA expression dictates the extent of inner ear development in conditional Dicer knockout mice. Dev Biol 2009; 328: 328-341.

10. Petri R, Malmevik J, Fasching L, Akerblom M, Jakobsson J. miRNAs in brain development. Exp Cell Res 2014; 321: 84-89.

11. Weston MD, Pierce ML, Rocha-Sanchez S, Beisel KW, Soukup GA. MicroRNA gene expression in the mouse inner ear. Brain Res 2006; 1111: 95-104.

12. Hirai M, Maeda $Y$, Fukushima K, Sugaya A, Kataoka $Y$, Nishizaki K. Expression analysis of microRNAs in murine cochlear explants. Neuroreport 2011; 22: 652-654.

13. Hei R, Chen J, Qiao L, Li X, Mao X, Qiu J et al. Dynamic changes in microRNA expression during differentiation of rat cochlear progenitor cells in vitro. Int $J$ Pediatr Otorhinolaryngol 2011; 75: 1010-1014.

14. Wang XR, Zhang XM, Zhen J, Zhang PX, Xu G, Jiang H. MicroRNA expression in the embryonic mouse inner ear. Neuroreport 2010; 21: 611-617.

15. Sacheli R, Nguyen L, Borgs L, Vandenbosch R, Bodson M, Lefebvre P et al. Expression patterns of miR-96, miR-182 and miR-183 in the development inner ear. Gene Expr Patterns 2009; 9: 364-370.

16. Friedman LM, Dror AA, Mor E, Tenne T, Toren G, Satoh T et al. MicroRNAs are essential for development and function of inner ear hair cells in vertebrates. Proc Natl Acad Sci USA 2009; 106: 7915-7920.

17. Hertzano R, Elkon R, Kurima K, Morrisson A, Chan SL, Sallin M et al. Cell type-specific transcriptome analysis reveals a major role for Zeb1 and miR-200b in mouse inner ear morphogenesis. PLoS Genet 2011; 7: e1002309.

18. Yan D, Xing Y, Ouyang X, Zhu J, Chen ZY, Lang H et al. Analysis of miR-376 RNA cluster members in the mouse inner ear. Int J Exp Pathol 2012; 93: 450-457.

19. Kuhn S, Johnson SL, Furness DN, Chen J, Ingham N, Hilton JM et al. miR-96 regulates the progression of differentiation in mammalian cochlear inner and outer hair cells. Proc Natl Acad Sci USA 2011; 108: 2355-2360.

20. Wang XR, Zhang XM, Du J, Jiang H. MicroRNA-182 regulates otocyst-derived cell differentiation and targets T-box1 gene. Hear Res 2012; 286: 55-63.

21. Groves AK, Zhang KD, Fekete DM. The genetics of hair cell development and regeneration. Annu Rev Neurosci 2013; 36: 361-381.

22. Kersigo J, D'Angelo A, Gray BD, Soukup GA, Fritzsch B. The role of sensory organs and the forebrain for the development of the craniofacial shape as revealed by Foxg1-cre-mediated microRNA loss. Genesis 2011; 49: 326-341.

23. Lewis MA, Quint E, Glazier AM, Fuchs H, De Angelis MH, Langford C et al. An ENU-induced mutation of miR-96 associated with progressive hearing loss in mice. Nat Genet 2009; 41 : 614-618.

24. Solda G, Robusto M, Primignani P, Castorina P, Benzoni E, Cesarani A et al. A novel mutation within the MIR96 gene causes non-syndromic inherited hearing loss in an Italian family by altering pre-miRNA processing. Hum Mol Genet 2012; 21: 577-585.

25. Mencia A, Modamio-Hoybjor S, Redshaw N, Morin M, Mayo-Merino F, Olavarrieta L et al. Mutations in the seed region of human miR-96 are responsible for nonsyndromic progressive hearing loss. Nat Genet 2009; 41: 609-613.

26. Weston MD, Pierce ML, Jensen-Smith HC, Fritzsch B, Rocha-Sanchez S, Beisel KW et al. MicroRNA-183 family expression in hair cell development and requirement of microRNAs for hair cell maintenance and survival. Dev Dyn 2011; 240: 808-819.

27. Cobb BS, Nesterova TB, Thompson E, Hertweck A, O'Connor E, Godwin J et al. T cell lineage choice and differentiation in the absence of the RNase III enzyme Dicer. J Exp Med 2005; 201: 1367-1373

28. Hebert JM, McConnell SK. Targeting of cre to the Foxg1 (BF-1) locus mediates loxP recombination in the telencephalon and other developing head structures. Dev Biol 2000; 222: 296-306.

29. Huyghe A, Van den Ackerveken P, Sacheli R, PrÃ Cvot PP, Thelen N, Renauld J et al. MicroRNA-124 Regulates Cell Specification in the Cochlea through Modulation of Strp4/5. Cell Rep 2015; 13: 31-42.

30. Tang KF, Ren H. The role of dicer in DNA damage repair. Int J Mol Sci 2012; 13: 16769-16778. 
31. Swahari V, Nakamura A, Baran-Gale J, Garcia I, Crowther AJ, Sons R et al. Essential function of dicer in resolving DNA damage in the rapidly dividing cells of the developing and malignant cerebellum. Cell Rep 2016; 14: 216-224.

32. Nakano K, Vousden KH. PUMA, a novel proapoptotic gene, is induced by p53. Mol Cell 2001; 7: 683-694.

33. Shibue T, Takeda K, Oda E, Tanaka H, Murasawa H, Takaoka A et al. Integral role of Noxa in p53-mediated apoptotic response. Genes Dev 2003; 17: 2233-2238.

34. Ruben RJ. Development of the inner ear of the mouse: a radioautographic study of terminal mitoses. Acta Otolaryngol 1967 Suppl 220:1-44.

35. Chen P, Zindy F, Abdala C, Liu F, Li X, Roussel MF et al. Progressive hearing loss in mice lacking the cyclin-dependent kinase inhibitor Ink4d. Nat Cell Biol 2003; 5: 422-426.

36. ElShamy WM, Fridvall LK, Ernfors P. Growth arrest failure, G1 restriction point override, and $S$ phase death of sensory precursor cells in the absence of neurotrophin-3. Neuron 1998; 21: 1003-1015.

37. Brunetta I, Casalotti SO, Hart IR, Forge A, Reynolds LE. beta3-integrin is required for differentiation in OC-2 cells derived from mammalian embryonic inner ear. BMC Cell Biol 2012; 13: 5.

38. Littlewood Evans A, Muller U. Stereocilia defects in the sensory hair cells of the inner ear in mice deficient in integrin alpha8beta1. Nat Genet 2000; 24: 424-428.

39. Davies D, Magnus C, Corwin JT. Developmental changes in cell-extracellular matrix interactions limit proliferation in the mammalian inner ear. Eur J Neurosci 2007; 25: 985-998.

40. Matilainen T, Haugas M, Kreidberg JA, Salminen M. Analysis of Netrin 1 receptors during inner ear development. Int J Dev Biol 2007; 51: 409-413.

41. Friedman LM, Dror AA, Mor E, Tenne T, Toren G, Satoh T et al. MicroRNAs are essential for development and function of inner ear hair cells in vertebrates. Proc Natl Acad Sci USA 2009; 106: 7915-7920.

42. Ho JJ, Metcalf JL, Yan MS, Turgeon PJ, Wang JJ, Chalsev M et al. Functional importance of Dicer protein in the adaptive cellular response to hypoxia. J Biol Chem 2012; 287: 29003-29020.

43. Pepin G, Perron MP, Provost P. Regulation of human Dicer by the resident ER membrane protein CLIMP-63. Nucleic Acids Res 2012; 40: 11603-11617.

44. Gantier MP, McCoy CE, Rusinova I, Saulep D, Wang D, Xu D et al. Analysis of microRNA turnover in mammalian cells following Dicer1 ablation. Nucleic Acids Res 2011; 39: 5692-5703.

45. Lal A, Pan Y, Navarro F, Dykxhoorn DM, Moreau L, Meire E et al. miR-24-mediated downregulation of $\mathrm{H} 2 \mathrm{AX}$ suppresses DNA repair in terminally differentiated blood cells. Nat Struct Mol Biol 2009; 16: 492-498.
46. Huang $\mathrm{H}$, Tian H, Duan Z, Cao Y, Zhang XS, Sun F. microRNA-383 impairs phosphorylation of $\mathrm{H} 2 \mathrm{AX}$ by targeting PNUTS and inducing cell cycle arrest in testicular embryonal carcinoma cells. Cell Signal 2014; 26: 903-911.

47. Francia S, Michelini F, Saxena A, Tang D, de Hoon M, Anelli V et al. Site-specific DICER and DROSHA RNA products control the DNA-damage response. Nature 2012; 488 : 231-235.

48. De Pietri Tonelli D, Pulvers JN, Haffner C, Murchison EP, Hannon GJ, Huttner WB. miRNAs are essential for survival and differentiation of newborn neurons but not for expansion of neural progenitors during early neurogenesis in the mouse embryonic neocortex. Development 2008; 135: 3911-3921.

49. Kawase-Koga $Y$, Low R, Otaegi G, Pollock A, Deng H, Eisenhaber $F$ et al. RNAase-II enzyme Dicer maintains signaling pathways for differentiation and survival in mouse cortical neural stem cells. J Cell Sci 2010; 123: 586-594

50. Chen W, Harbeck MC, Zhang W, Jacobson JR. MicroRNA regulation of integrins. Transl Res 2013; 162: 133-143.

51. Davies D, Holley MC. Differential expression of alpha 3 and alpha 6 integrins in the developing mouse inner ear. J Comp Neurol 2002; 445: 122-132.

52. Stupack DG, Cheresh DA. Get a ligand, get a life: integrins, signaling and cell survival. J Cell Sci 2002; 115: 3729-3738

53. Margadant C, Monsuur HN, Norman JC, Sonnenberg A. Mechanisms of integrin activation and trafficking. Curr Opin Cell Biol 2011; 23: 607-614.

54. Long K, Moss L, Laursen L, Boulter L, ffrench-Constant C. Integrin signalling regulates the expansion of neuroepithelial progenitors and neurogenesis via Wnt7a and Decorin. Nat Commun 2016; 7: 10354.

55. Li G, Luna C, Qiu J, Epstein DL, Gonzalez P. Targeting of integrin beta1 and kinesin 2alpha by microRNA 183. J Biol Chem 2010; 285: 5461-5471.

56. Steenhard BM, Vanacore R, Friedman D, Zelenchuk A, Stroganova L, Isom K et al. Upregulated expression of integrin alpha1 in mesangial cells and integrin alpha3 and vimentin in podocytes of Col4a3-null (Alport) mice. PLOS ONE 2012; 7: e50745.

57. Muzio L, Mallamaci A. Foxg1 confines Cajal-Retzius neuronogenesis and hippocampal morphogenesis to the dorsomedial pallium. J Neurosci 2005; 25: 4435-4441.

58. Shi S, Yu L, Chiu C, Sun Y, Chen J, Khitrov G et al. Podocyte-selective deletion of dice induces proteinuria and glomerulosclerosis. J Am Soc Nephrol 2008; 19: 2159-2169.

59. Rivolta MN, Grix N, Lawlor P, Ashmore JF, Jagger DJ, Holley MC. Auditory hair cell precursors immortalized from the mammalian inner ear. Proc Biol Sci 1998; 265: 1595-1603. 